\title{
Territorio y redes alimentarias alternativas: experiencias en la ciudad de Sevilla*
}

\author{
Gema González-Romero \\ Fulgencio Cánovas-García \\ Universidad de Sevilla. Departamento de Geografía Humana \\ gemagonzalez@us.es \\ fcgarcia@us.es
}

\section{Resumen}

Las redes alimentarias alternativas son un fenómeno de marcado carácter urbano con una expansión significativa durante las primeras décadas del siglo xxi. Se vinculan a movimientos ciudadanos en respuesta a los impactos socioeconómicos, ambientales y territoriales de un régimen alimentario globalizado y financiarizado, así como a la creciente preocupación por la seguridad y la calidad alimentarias. El objetivo de este artículo es analizar dichas redes en Sevilla, prestando especial atención a sus implicaciones territoriales, aspecto poco tratado hasta ahora en la literatura que aborda esta temática. Se ha aplicado una metodología mixta: cualitativa (entrevistas semiestructuradas y observación virtual) y cuantitativa (bases de datos y redes sociales). En Sevilla, las iniciativas vinculadas a redes alimentarias alternativas están arraigadas en determinados barrios y sus implicaciones territoriales sobrepasan el ámbito periurbano. Pese a sus limitaciones, no puede dejar de valorarse su capacidad para generar proyectos colectivos en favor de un sistema alimentario más justo y sostenible.

Palabras clave: redes alimentarias alternativas; espacios económicos alternativos; ciudadanía alimentaria; acción colectiva; Sevilla

* Este artículo se encuadra en los proyectos de investigación «Espacios y prácticas económicas alternativas para la construcción de la resiliencia en las ciudades españolas» CSO201565452-R (Mineco/FEDER) y «Sistemas agroalimentarios multifuncionales y territorializados en España. Metodologías para su estudio y análisis de casos en Andalucía y Extremadura» PID2019-105711RB-C62. 
Resum. Territori i xarxes alimentàries alternatives: experiències a la ciutat de Sevilla

Les xarxes alimentàries alternatives són un fenomen de marcat caràcter urbà i amb una expansió significativa durant les primeres dècades de segle Xxi. Es vinculen amb moviments ciutadans en resposta als impactes socioeconòmics, ambientals i territorials d'un règim alimentari globalitzat i financiaritzat, així com a la creixent preocupació per la seguretat i la qualitat alimentàries. L'objectiu d'aquest article és analitzar aquestes xarxes a Sevilla, prestant especial atenció a les seves implicacions territorials, aspecte poc tractat fins ara en la literatura que aborda aquesta temàtica. S'ha aplicat una metodologia mixta: qualitativa (entrevistes semiestructurades i observació virtual) i quantitativa (bases de dades i xarxes socials). A Sevilla, les iniciatives vinculades a xarxes alimentàries alternatives estan arrelades en determinats barris i les seves implicacions territorials sobrepassen l'àmbit periurbà. Malgrat les seves limitacions, no es pot deixar de valorar la seva capacitat per generar projectes col-lectius en favor d'un sistema alimentari més just i sostenible.

Paraules clau: xarxes alimentàries alternatives; espais econòmics alternatius; ciutadania alimentària; acció col-lectiva; Sevilla

Résumé. Territoire et réseaux alimentaires alternatifs : expériences dans la ville de Séville

Les réseaux alimentaires alternatifs sont un phénomène à caractère urbain marqué et en forte expansion au cours des premières décennies du xxıe siècle. Ils se lient aux mouvements citoyens en réponse aux impacts socio-économiques, environnementaux et territoriaux d'une alimentation mondialisée et financiarisée, ainsi qu'au souci croissant de sécurité et de qualité des aliments. L'objectif de cet article est d'analyser ces réseaux à Séville, en portant une attention particulière à leurs implications territoriales, un aspect qui n'a pas été traité jusqu'à présent dans la littérature traitant de cette question. Une méthodologie mixte a été appliquée : qualitative (entretiens semi-structurés et observation virtuelle) et quantitative (bases de données et réseaux sociaux). À Séville, les initiatives liées aux réseaux alimentaires alternatifs sont ancrées dans certains quartiers et leurs implications territoriales dépassent le périmètre périurbain : malgré leurs limites, leur capacité à générer des projets collectifs en faveur d'un système alimentaire plus juste et plus durable ne peut être négligée.

Mots-clés : réseaux alimentaires alternatifs ; des espaces économiques alternatifs ; citoyenneté alimentaire ; action collective ; Séville

Abstract. Territory and alternative food networks: experiences in the city of Seville

Alternative food networks are a phenomenon of a markedly urban nature and with a major expansion during the first decades of the $21^{\text {st }}$ century. They link with citizen movements in response to the socio-economic, environmental and territorial impacts of a globalized and financialized food system, as well as the growing concern for food safety and quality. The aim of this article is to analyze these networks in Seville, paying special attention to its territorial implications, an aspect little dealt with so far in the literature that addresses this issue. A mixed methodology has been applied: qualitative (semi-structured interviews and virtual observation) and quantitative (databases and social networks). In Seville, initiatives linked to alternative food networks are rooted in certain neighborhoods and their territorial implications go beyond the peri-urban area. Despite its limitations, its ability to generate collective projects in favor of a fairer and more sustainable food system cannot be overlooked.

Keywords: alternative food networks; alternative economic spaces; food citizenship; collective action; Seville 


\section{Sumario}

1. Introducción

2. Metodología

3. Apuntes teóricos y contextualización de las redes alimentarias alternativas
4. Resultados

5. Discusión y conclusiones

Agradecimientos

Referencias bibliográficas

\section{Introducción}

En las últimas décadas, los profundos cambios que ha experimentado el sistema agroalimentario han acentuado el alejamiento entre los productores de alimentos y los consumidores, a la vez que se ha transitado hacia un régimen alimentario marcado por la globalización y la financiarización, donde la producción y la comercialización se concentran en manos de un número reducido de grupos y empresas multinacionales que se erigen en los principales agentes de la organización agroalimentaria mundial (Burch y Lawrence, 2009; McMichael, 2009).

De forma paralela, se han extendido las críticas hacia los modelos imperantes de producción, distribución y consumo de alimentos, a la vez que la inquietud por la seguridad y la calidad alimentarias, la desafección al sistema agroalimentario, la reivindicación de la soberanía alimentaria, la sensibilidad hacia la problemática ambiental, la preocupación por los costes energéticos de la distribución y comercialización de alimentos, y la incertidumbre ante el escenario de cambio climático. Estas inquietudes en ascenso han motivado la proliferación en los ámbitos urbanos de iniciativas ciudadanas frente al orden alimentario establecido, que se articulan e interrelacionan conformando una red.

Las redes alimentarias alternativas (RAA) se pueden definir como modalidades de abastecimiento alimentario que, frente al modelo hegemónico de la producción industrial y la gran distribución, abogan por nuevas formas de relación y colaboración productor-consumidor. Estas se presentan como una oportunidad para los productores, quienes, al buscar desvincularse de un sistema alimentario globalizado y financiarizado, se conectan a través de canales cortos de comercialización con unos consumidores que, por diferentes motivaciones (salud, ecología, política, ética e, incluso, por moda), persiguen la soberanía alimentaria, la seguridad, la calidad, lo natural, lo ecológico, la justicia social, lo artesanal, la proximidad y la autenticidad en la alimentación. Entre las RAA se encuentran toda una variedad de iniciativas, tales como agrupaciones de productores, mercados de productores, cooperativas, grupos de consumo agroecológicos, huertos colectivos...

Estas RAA emergen y se reproducen fundamentalmente en los ámbitos urbanos, al ser estos los espacios de consumo y concentración de capital, los que se han mostrado especialmente vulnerables a la crisis (acicate para la profusión de este tipo de iniciativas ciudadanas) y los que concentran buena parte de los movimientos ciudadanos de reacción y acción frente al statu quo (Goldberg, 
1991). Sobre estos movimientos se han apoyado, en parte, algunas de las prácticas alimentarias alternativas.

El objetivo de este artículo es analizar las RAA desarrolladas en la ciudad de Sevilla, con especial atención a sus implicaciones territoriales. Este último aspecto ha sido poco tratado hasta ahora en la literatura que aborda esta temática y supone una de las aportaciones principales de este artículo. Se pretende, pues, responder a las siguientes preguntas de investigación: ¿qué presencia tienen las RAA en la ciudad de Sevilla?, ¿cuál ha sido su evolución?; ¿quiénes son sus actores?, ¿cómo se conectan?; ¿qué relación existe entre dichas prácticas y el espacio urbano?, ¿existen ámbitos con cierto grado de concentración?, ¿qué factores las propician?; ¿qué territorios se incorporan a estas redes?, ¿hasta dónde se extienden?

La hipótesis de partida es que las RAA, pese a ser aún un fenómeno urbano emergente $y$, por tanto, con una capacidad limitada para transitar hacia un nuevo sistema alimentario, tienen repercusiones territoriales significativas, que, además de proyectarse en la escala urbana, la traspasan, extendiéndose incluso más allá del ámbito periurbano.

\section{Metodología}

La metodología aplicada en la investigación ha sido de carácter mixto: cualitativa, a base de entrevistas semiestructuradas y la observación virtual; y cuantitativa, a partir de análisis de bases de datos y de redes sociales.

Para poder cubrir el vacío de información existente, pues no existen estadísticas publicadas sobre las prácticas inscritas en las RAA, la investigación ha partido de la elaboración de una base de datos sobre las iniciativas y los actores involucrados. Su realización no ha sido tarea fácil, y ha tenido que superar la dispersión de los datos por diferentes páginas webs, catálogos y directorios pertenecientes a organizaciones, colectivos y administración local.

Descubrir quiénes son los actores de estas redes ha sido el paso previo para poder llevar a cabo un trabajo de campo a base de entrevistas semiestructuradas a informantes claves ${ }^{1}$, que han permitido comprender mejor el fenómeno. Además, con la información recogida se ha podido elaborar una cartografía específica de productores (agrícolas, ganaderos y agroalimentarios), de lugares de distribución (mercados de productores agrarios, mercados sociales y otros locales de reparto) y de cooperativas, asociaciones y grupos de consumo agroecológico, lo que ha permitido identificar y cartografiar la geografía de las RAA de Sevilla.

1. Se han realizado un total de diez entrevistas a: siete usuarios, un encargado de una cooperativa de consumo, un promotor de una asociación productores-consumidores y una investigadora y activista. Las entrevistas se han estructurado en secciones comunes para las diferentes prácticas que integran las RAA, en las que se abordan cuestiones relativas a la organización, actividades, formas de participación, beneficios obtenidos y perspectivas de futuro. A estas se añade un bloque específico de preguntas para cada tipo de práctica alimentaria alternativa. 
Junto con todo lo anterior, no hay que dejar de señalar la información cualitativa derivada de la observación virtual de diferentes webs que, en algunos casos, describen su historia, principios, proyectos, colaboraciones y forma de funcionamiento, lo que ha facilitado la comprensión de sus trayectorias, organizaciones y argumentos, así como de las implicaciones territoriales que subyacen tras estas iniciativas alimentarias.

En esta investigación se ha incorporado la perspectiva relacional, recurriendo al análisis de las redes sociales. Su estudio puede desarrollarse a partir de la aplicación de diferentes métodos y técnicas (Wasserman y Faust, 1994; Molina, 2001; Borgatti et al., 2013; Domínguez y Hollstein, 2014). En este caso, se ha elaborado un sociograma y analizado tanto la densidad general de la red como las posiciones de centralidad y poder de los diferentes actores, para lo que se ha empleado el programa Ucinet.

\section{Apuntes teóricos y contextualización de las redes alimentarias alternativas}

\subsection{Prácticas económicas alternativas y redes alimentarias alternativas en la investigación geográfica}

La crisis financiera de 2008 favoreció la proliferación de iniciativas ciudadanas que, basadas en redes de apoyo mutuo, confianza y colaboración, cuestionan el sistema económico, político y social, y reivindican modelos alternativos que aúnen democracia, compromiso social y sostenibilidad medioambiental. De este modo, «las prácticas de colaboración ciudadana toman especial relevancia en un contexto de crisis donde se intensifican las dinámicas excluyentes del mercado (desahucios, desempleo, pobreza, desigualdades crecientes...) y donde se hace evidente la incapacidad de los poderes públicos de dar respuesta a necesidades sociales en aumento» (Blanco et al., 2016: 249).

El interés por las prácticas de carácter alternativo ha recalado en los estudios de geografía incluso antes de la crisis financiera. La publicación, en 1997, de The End of Capitalism (As We Knew It): A Feminist Critique of Political Economy, de Gibson-Graham, fue esencial en la definición de un programa investigador en torno a las "economías diversas». Tanto en esta como en publicaciones posteriores, Gibson-Graham (2006, 2007, 2008) conceptualizaron y definieron "economías diversas y economías comunitarias», que, bajo el principio de la resocialización de las relaciones económicas, privilegian el cuidado de la comunidad local y del medio ambiente (Gibson-Graham, 2006: 81).

Otra referencia de especial interés es la publicación Alternative Economic Spaces, de Leyshon et al. (2003), donde ya se identificaba la emergencia de espacios económicos alternativos, resultado de la proliferación de prácticas asociadas a sistemas locales de intercambio y comercio, cooperativas de crédito y otras iniciativas de economía social.

A partir de estas primeras contribuciones, las aportaciones desde la geografía a esta temática han aumentado a un ritmo significativo, lo que ha revelado 
el interés académico por una multitud de prácticas que se agrupan bajo el término impreciso de alternativas (North, 2005; Fickey, 2011; Zademach y Hildebrand, 2013; Fickey y Hanrahan, 2014; White y Williams, 2016; Diprose, 2017), hasta el punto de que algunos autores afirman que se han convertido en una de las temáticas emergentes dentro de los estudios de geografía económica (Barnes y Christophers, 2018; Méndez, 2020).

En España, los primeros estudios relacionados con prácticas económicas alternativas provienen del ámbito de la sociología. La obra de Conill et al. (2012) Otra vida es posible. Prácticas económicas alternativas durante la crisis, centrada en el análisis de prácticas económicas alternativas en Cataluña, es un referente para esta línea de investigación. Desde la geografía económica, las primeras revisiones y reflexiones de carácter teórico sobre este tipo de iniciativas y prácticas se realizan años después (Méndez, 2015; Sánchez Hernández, 2017). En 2019, se publicó la obra colectiva Espacios y prácticas económicas alternativas en las ciudades españolas (Sánchez Hernández, coord., 2019), que reúne los resultados de un proyecto de investigación sobre ocho ciudades españolas. Junto a estas, cabe señalar otras contribuciones basadas en las experiencias locales de prácticas económicas alternativas (Méndez y Monteserín, 2017; Michelini et al., 2017; Sánchez Hernández et al., 2017; Pascual et al., 2018; Benito del Pozo y López- González, 2019; Caravaca y González-Romero, 2019; Climent y Lardiés-Bosque, 2019; González-Romero y Caravaca, 2020).

Por lo que se refiere a las RAA, existe una abundante bibliografía y son diversas las disciplinas que se han aproximado a esta temática de investigación, entre las que se encuentran la economía, la sociología, la antropología y, de forma destacada, la geografía (Whatmore y Thorne, 1997; Marsden et al., 2000; Renting et al., 2003; Sage, 2003; Sonnino y Marsden, 2006; Venn et al., 2006; Maye et al., 2007; Jarosz, 2008; Harris, 2010; Goodman et al., 2012). A finales de los años noventa, Whatmore y Thorne (1997) se referían a las RAA utilizando el término específico de "geografías alternativas de la alimentación», mientras que Marsden et al. (2000) utilizan el de "cadenas alimentarias alternativas», por su parte, Renting et al. (2003) emplearon el de «redes alimentarias alternativas» (Corsi et al., 2018).

En el caso de España, como recoge Sánchez Hernández (2009), la investigación de los geógrafos sobre RAA se ha centrado en los estudios sobre agricultura ecológica (López Ontiveros y Moya, 1994; López García, 1999; Armesto López, 2007; Alberdi, 2018) y denominaciones de origen (Aparicio et al., 2008; Loscertales et al., 2011; Freitas y Canto, 2014; Esteban y Climent, 2017). Como señalaba este autor, la aproximación a este tipo de iniciativas no se ha realizado desde una perspectiva urbana, sino desde su consideración como herramientas para la promoción de un desarrollo rural integrado enfatizando la dimensión productiva del sistema agroalimentario y sin prestar la suficiente atención a las fases de distribución y consumo, que son mayoritariamente urbanas. Recientemente, se ha avanzado en una línea de investigación que analiza las RAA en el contexto de las prácticas económicas alternativas y que pone el acento en las relaciones entre productores y consumidores (Mén- 
dez y Monteserín, 2017; Michelini et al., 2017; Sánchez Hernández, 2019). A estos trabajos sobre actividades y prácticas asociadas a RAA se han añadido otros sobre agricultura urbana y periurbana, y huertos urbanos (Zárate, 2015; Domene et al., 2017; Mata Olmo, 2018; Larrubia et al., 2020; Yacamán et al., 2020). Aun así, como señala Mata Olmo (2018), las RAA siguen siendo una temática de investigación por desarrollar en los estudios sobre los sistemas agroalimentarios urbanos y metropolitanos.

\subsection{Iniciativas económicas ciudadanas frente al orden establecido: las redes alimentarias alternativas}

Las iniciativas en torno a las RAA han cobrado mayor relevancia y se han difundido, junto con otras prácticas económicas, como respuestas a la crisis del modelo socioeconómico imperante y como alternativas a un modelo en crisis. De este modo, las RAA pueden considerarse como una expresión más de las prácticas económicas alternativas, ya que comparten principios, objetivos, actores, organización y funcionamiento.

$\mathrm{Al}$ igual que otras prácticas económicas alternativas, las iniciativas que proponen otro orden alimentario representan una estrategia de innovación social tanto en sus objetivos como en su organización, formas y funcionamiento. Tanto unas como otras pretenden hacer frente al capitalismo y comparten unos mismos valores e ideologías de carácter progresista y transformador. Este conjunto de prácticas impulsa el desarrollo de una economía alternativa más localizada, eficiente, sostenible e inclusiva, que pretende resolver las necesidades de las personas más allá del mercado y el lucro (Gibson- Graham, 2008; Healey, 2009; Jones y Murphy, 2011; Psarikidou y Szerszynski, 2012; Gritzas y Kavoulakos, 2016).

Respecto a su organización, la confianza sustenta y la colaboración articula las relaciones, la solidaridad se convierte en su principio ético y la transformación política y socioeconómica es su objetivo. Estas iniciativas tienen motivaciones diversas y defienden valores no economicistas (sostenibilidad, emancipación, anclaje territorial, solidaridad...), pero también pueden llegar a ser el resultado de estrategias de adaptación e, incluso, resiliencia en un escenario de crisis y creciente exclusión social.

En este contexto, las RAA se presentan como propuestas transformadoras frente al modelo dominante de producción, distribución y comercialización de alimentos, sobre la base de nuevos vínculos y relaciones entre productorconsumidor que, a partir de lazos sociales, empoderan a la población de un territorio garantizando su sostenibilidad económica y ecológica (López García, 2015).

El crecimiento de este tipo de iniciativas alimentarias se hace cada vez más visible en los ámbitos urbanos y se vincula con la emergencia de movimientos ciudadanos en respuesta a los impactos sociales, ambientales y territoriales de la globalización agroalimentaria, por lo que, en algunos casos, llegan a conectar con el movimiento antiglobalización que germinó a finales de los años 
noventa (Vivas, 2010). Así, algunas de estas RAA se inspiran en ideologías anticapitalistas y quienes las promueven participan en movimientos sociales y de la lucha política que, a través del sistema alimentario, ponen en práctica relaciones de intercambio no capitalistas basadas en el valor de uso y no en el de cambio (López García, 2015). El sistema agroalimentario actual, crecientemente industrializado, regulado, globalizado y financiarizado, describe los rasgos definitorios de la última fase del sistema capitalista, por lo que transformar el sistema alimentario implica cuestionar una de las bases del sistema capitalista. En el mundo rural, los movimientos sociales que reprueban la injusta distribución del valor generado en la cadena alimentaria tienen uno de sus exponentes en Vía Campesina, organización que defiende la sostenibilidad económica, ambiental y social de la producción, distribución y consumo de alimentos sobre la base de la soberanía alimentaria de los pueblos (Windfuhr y Jonsén, 2005; Patel, 2009; Timmermann, et al., 2018).

Pero no todos los que participan en estas prácticas alimentarias alternativas se identifican con movimientos anticapitalistas y antiglobalización, sino que también están quienes, más próximos al ecologismo, se preocupan por la salud y desconfían del actual modelo agroalimentario (Calle et al., 2009; Callejo, 2009; Vivas, 2010). Así, los principios de la agroecología, que inciden sobre los valores ecológicos y sociales de los sistemas agroalimentarios, también pueden identificarse en las prácticas alimentarias alternativas (Altieri, 1987; Guzmán et al., 2000; Gliessman, 2007; Sevilla y Soler, 2010). En relación con lo anterior, se explica que los proyectos vinculados a la agroecología y a la agricultura urbana estén en ascenso en las últimas décadas, no solo por una motivación ecológica, sino porque la agricultura urbana se concibe como una "herramienta de empoderamiento para reclamar el derecho a la ciudad de grupos sociales habitualmente ignorados en el diseño y construcción de la ciudad» (Dimuro et al., 2013: 41).

Igualmente, entre los participantes de este tipo de prácticas se reconocen a algunos de los más afectados por la crisis, por lo que pueden identificarse también ciertos rasgos de la agricultura social en actividades inscritas en las RAA (Di Iacovo, 2010; Tulla et al., 2015; García-Llorente et al., 2016; Guirado, et al., 2018).

Corsi et al. (2018) realizan una recopilación de los diferentes criterios que aparecen recogidos en la literatura y que ayudan a definir las RAA. Entre dichos criterios se incluyen las proximidades económica, geográfica, cultural y social entre productor y consumidor (Marsden et al., 2000; Renting et al., 2003; Goodman y Goodman, 2009; Sevilla Guzmán et al., 2012):

- La proximidad económica es uno de los criterios más consensuados y se basa en la longitud de la cadena de distribución, medida en función del número de intermediarios entre productores y consumidores.

- Por su parte, la proximidad geográfica enfatiza en el criterio del origen local de los alimentos e incide también en su objetivo medioambiental (reducir el consumo energético y las emisiones asociadas a la distribución resul- 
tan cruciales en un escenario de crisis energética y emergencia climática). Además, dicha proximidad geográfica propicia la generación de vínculos de confianza que, a su vez, son la base para el establecimiento de las redes de colaboración y cooperación que soportan este modelo alimentario alternativo (Sevilla Guzmán et al., 2012). Aun así, autores como Marsden et al. (2000) y Renting et al. (2003) prescinden de la distancia geográfica como criterio básico para definir las RAA.

- La proximidad cultural entronca con el valor simbólico y las raíces culturales de los alimentos locales, lo que otorga autenticidad al producto (Renting et al., 2003).

- En cuanto a la proximidad social, esta se centra en el criterio de embeddedness o enraizamiento, que considera la involucración del consumidor con los productores y el lugar de producción, y que se deriva de la información y del conocimiento tanto de los productores como de los métodos de producción empleados (Marsden et al., 2000).

Otros autores apuntan a que la proximidad entre productor y consumidor va más allá del número de intermediarios entre los mismos, o de la proximidad geográfica, cultural o social, y entienden que esta proximidad parte de «la redefinición práctica y activa de las relaciones de poder dentro del sistema agroalimentario a favor simultáneamente de productores/as alimentarios (...) y consumidores/as» (Sevilla Guzmán et al., 2012: 49). Es decir, que las relaciones se establezcan de igual a igual frente a la jerarquía de una lógica de mercado.

Esto último dirige nuevamente la atención hacia las redes y relaciones de colaboración y cooperación sobre las que se sustentan las propuestas alimentarias alternativas. Estas iniciativas ciudadanas se articulan a partir de una estructura organizativa en forma de red donde, frente a las relaciones de carácter vertical y jerárquico, predominan las relaciones entre iguales. «Sus integrantes mantienen relaciones de reciprocidad densas, con vínculos materiales y simbólicos que permiten acumular capital relacional y son origen de culturas de pertenencia, con normas y valores compartidos» (Michelini et al., 2017: 683).

Bajo la denominación de RAA se aglutinan actividades diversas que, en algunos casos, tienen como único nexo el presentarse como fórmulas contrahegemónicas al modelo establecido. Existen propuestas en las que se consideran como tales una amplia variedad de proyectos: figuras geográficas de calidad alimentaria, certificación privada de alimentos, alimentos ecológicos, agricultura comunitaria, grupos y cooperativas de consumo, mercados de productores, venta directa... (Sánchez Hernández, 2009). Otras, en cambio, entienden que las RAA solo se corresponden con iniciativas y proyectos colectivos que, además de identificarse con experiencias agroecológicas de canales cortos de comercialización y consumo reflexivo, fundamentalmente, deben generar innovaciones sociales y promover dinámicas de cambio social (Sevilla Guzmán et al., 2012).

Unas y otras parecen coincidir en identificar las RAA con huertos sociales, mercados de productores, asociaciones de productores y consumidores, coope- 
rativas y grupos de consumo agroecológico. Mientras que los huertos sociales son experiencias de recuperación de la actividad agrícola urbana, a la que se añaden nuevas funcionalidades sociales y ambientales, el resto se presentan como opciones de comercialización y consumo responsables basadas en la confianza, el apoyo mutuo y la cercanía geográfica entre productor y consumidor.

\section{Resultados}

\subsection{Origen y evolución de las prácticas alimentarias alternativas}

Las primeras iniciativas asociadas a las RAA comienzan en la ciudad en los años noventa, fruto de la preocupación ciudadana por la seguridad y la calidad de los alimentos, así como por el medio ambiente; desde entonces, al menos, son 36 las prácticas desarrolladas ${ }^{2}$ (tabla 1).

Entre las experiencias iniciales se inscriben los primeros huertos urbanos (Miraflores y San Jerónimo) y la única cooperativa de consumo agroecológico (La Ortiga). Mientras que los huertos urbanos surgen de reivindicaciones de asociaciones de vecinos y colectivos para la gestión comunitaria de espacios verdes y la recuperación de la agricultura urbana (Puente, 2012; Dimuro et al., 2013; Dimuro, 2016), la cooperativa es impulsada por ciudadanos preocupados por la producción ecológica y en apoyo al desarrollo rural.

Entre 2003 y 2008 el incremento de estas iniciativas fue sostenido. En este período arrancaron ocho proyectos, fruto de renovados planteamientos e intereses. La preocupación por una alimentación saludable, la recuperación de la agricultura urbana y el medioambiente siguen presentes, a los que se suma la defensa de la soberanía alimentaria y de los bienes comunales frente a la globalización y el capitalismo. Se entiende que el consumo es un acto que va más allá de la satisfacción de una necesidad básica y se convierte en una herramienta para la transformación social, política y económica. Algunas de estas experiencias alimentarias alternativas resultan de «reivindicaciones desde los principios del feminismo anticapitalista, en pos de apoyar la construcción de alternativas a la actual globalización agroalimentaria, capitalista y patriarcal» (A-liadas por la soberanía alimentaria), y otras actúan desde la «acción política, como proceso [...] que impulsa la participación activa de la ciudadanía en el control y gestión de los recursos comunitarios» (El Enjambre sin Reina). De esta etapa es también el Huerto del Rey Moro, de gran simbolismo para los movimientos de contestación social en la ciudad, y resultado de la okupación por los vecinos de una antigua huerta del siglo Xv para preservarla de su urbanización.

Una tercera oleada de nuevos proyectos se inaugura con la crisis de 2008, que marcó un hito en la evolución de estas experiencias alimentarias alternativas. El desempleo y el deterioro del estado de bienestar propiciaron la movilización ciudadana en la búsqueda de alternativas al sistema económico o, al

2. Durante la investigación no se ha podido determinar el número exacto de los grupos de consumo agroecológico. A diferencia de otras iniciativas, no cuentan con webs propias y su huella digital es menor; en las entrevistas, tampoco se han aportado cifras precisas. 
Tabla 1. Prácticas alimentarias alternativas

\begin{tabular}{|c|c|c|c|c|}
\hline & $\begin{array}{c}1 .^{\text {a }} \text { etapa: } \\
1992-1999\end{array}$ & $\begin{array}{c}2 .^{\mathrm{a}} \text { etapa: } \\
2000-2008\end{array}$ & $\begin{array}{c}3 .^{a} \text { etapa } \\
2009-2020\end{array}$ & $1992-2020$ \\
\hline Bancos de semillas & & 1 & 2 & 3 \\
\hline Huertos urbanos & 2 & 4 & 7 & 13 \\
\hline Mercados de productores agrarios & & & 2 & 2 \\
\hline Asociaciones/redes de productores y consumidores & & 1 & 3 & 4 \\
\hline Grupos de consumo agroecológico & & 1 & 7 & 8 \\
\hline Cooperativas de consumo agroecológico & 1 & & & 1 \\
\hline Mercados sociales & & & 3 & 3 \\
\hline Otras & & 1 & 1 & 2 \\
\hline Total & 3 & 8 & 25 & 36 \\
\hline
\end{tabular}

Fuente: elaboración propia.

menos, de propuestas para mitigar algunos de sus problemas. En esta etapa surgieron 25 iniciativas: dos bancos de semillas, siete huertos urbanos, otros tantos grupos de consumo agroecológico, dos mercados de productores, tres asociaciones/redes de productores-consumidores y tres mercados sociales, a los que se suman otras iniciativas.

\subsection{Redes alimentarias alternativas: actores y vínculos}

Quienes promueven e integran las RAA no conforman un grupo homogéneo, y entre los mismos existen diversas motivaciones para participar. Por un lado, se identifican actores vinculados a núcleos de militancia política y activismo ciudadano que consideran que la lógica del capitalismo es incompatible con la justicia social y la sostenibilidad ambiental, asociados a movimientos ecologistas, antiglobalización o anticapitalistas. Estos movimientos sociales, integrados a su vez en otras redes, contribuyen a articular y contextualizar estas experiencias alimentarias en un proyecto más ambicioso y transformador hacia la construcción de alternativas económicas, sociales y políticas en la ciudad.

En Sevilla, la base social y los grupos promotores de muchas de estas actuaciones establecen algún vínculo con Ecologistas en Acción, la Red de Decrecimiento Sevilla, el Sindicato Andaluz de Trabajadores (SAT) y, en menor medida, las asambleas del $15 \mathrm{M}^{3}$. El cuestionamiento de la economía convencional y la contribución a mejorar la sociedad y el medio ambiente se revelan como principales motivaciones en las entrevistas.

Por otro lado, estarían aquellos actores que se acercan a estas prácticas por ocio o por haber sido afectados por la crisis. En este grupo se encuentran parte de los usuarios de los huertos urbanos, que, en su mayoría, fueron impulsados

3. En 2011 y en el contexto de la crisis iniciada en 2008, en muchas ciudades españolas tuvieron lugar movilizaciones ciudadanas que impulsaron la organización de asambleas descentralizadas por barrios en las que se proponían alternativas al modelo económico y las formas de gobierno. Este movimiento ciudadano se conoce como 15M. 
desde asociaciones de vecinos. En una encuesta realizada por el ayuntamiento a sus usuarios, se destacaban como principales motivaciones el ocio y la alimentación saludable, a las que se sumaba el trabajo en el huerto como medida complementaria al sustento familiar (Ayuntamiento de Sevilla, 2018). Similares conclusiones se derivaban de un estudio previo sobre movimientos comunitarios tras la crisis en la ciudad de Sevilla (Barrera Algarín et al., 2017).

Finalmente, no se pueden obviar a aquellos actores que se incorporan a estas prácticas atraídos por nuevos estilos de vida y consumo derivados de la emergencia de una nueva cultura de la alimentación. Priorizar una alimentación saludable se presenta como una necesidad entre algunos de los entrevistados.

La red que conforman las iniciativas alimentarias alternativas está integrada no solo por las 36 identificadas, sino también por otras prácticas económicas alternativas, organizaciones ecologistas, sindicatos e incluso la administración local (figura 1). Además, como se ha plasmado en las entrevistas, no es extraño que coincidan los mismos actores como promotores o copartícipes de diferentes prácticas.

La diversidad y el número de actores que colaboran en la red hacen que sea más difícil alcanzar su máximo potencial relacional, lo que puede explicar que la densidad general de la red, calculada en función del número de vínculos establecidos entre los nodos respecto al total posible, sea baja (8\%).

La red se estructura, a su vez, en varias subredes: a) la articulada por El Enjambre sin Reina y Ecologistas en Acción, que es la central y de mayor extensión; b) la conformada en torno a la Red Ecoartesana y que agrupa a la mayoría de los grupos de consumo agroecológicos; $c$ ) la organizada alrededor de la cooperativa La Ortiga y que enlaza a buena parte de los proyectos que asocian a productor-consumidor y a los mercados de productores; y d) la liderada por el ayuntamiento y que integra a los diferentes huertos urbanos.

Con relación a la centralidad y el poder de intermediación de cada actor, el más destacado es El Enjambre sin Reina, pues, como refleja el sociograma, es el que cuenta con más vínculos directos e indirectos y es, en consecuencia, el de mayor capacidad de intermediación y de cohesión de la red. Se trata de un colectivo que, mediante acciones en el ámbito de la educación ambiental y la producción agroecológica, pretende favorecer el tránsito hacia una sociedad más justa y sostenible. Su diversidad de roles, actuaciones y proyectos explica su papel central dentro de la red. Así, ha pasado de grupo de consumo a colectivo de autoproducción y autoconsumo, a productores que sirven a grupos de consumo, hasta crear su propio mercado social. Otro de los actores que sobresalen por su centralidad en la red es Ecologistas en Acción, pues ha impulsado y acompañado a un amplio número de proyectos agroecológicos en la ciudad. Tras estos hay que destacar a la Red Ecoartesana y a la cooperativa La Ortiga. Por su parte, el Ayuntamiento de Sevilla se integra en la red tras sustituir a las asociaciones de vecinos en la promoción y gestión de los huertos urbanos.

Aunque no destaquen por su centralidad en la red, el papel de los centros socioculturales autogestionados se revela de interés. $\mathrm{Al}$ ser lugares de encuentro 
Figura 1. Sociograma* de la red alimentaria alternativa en Sevilla

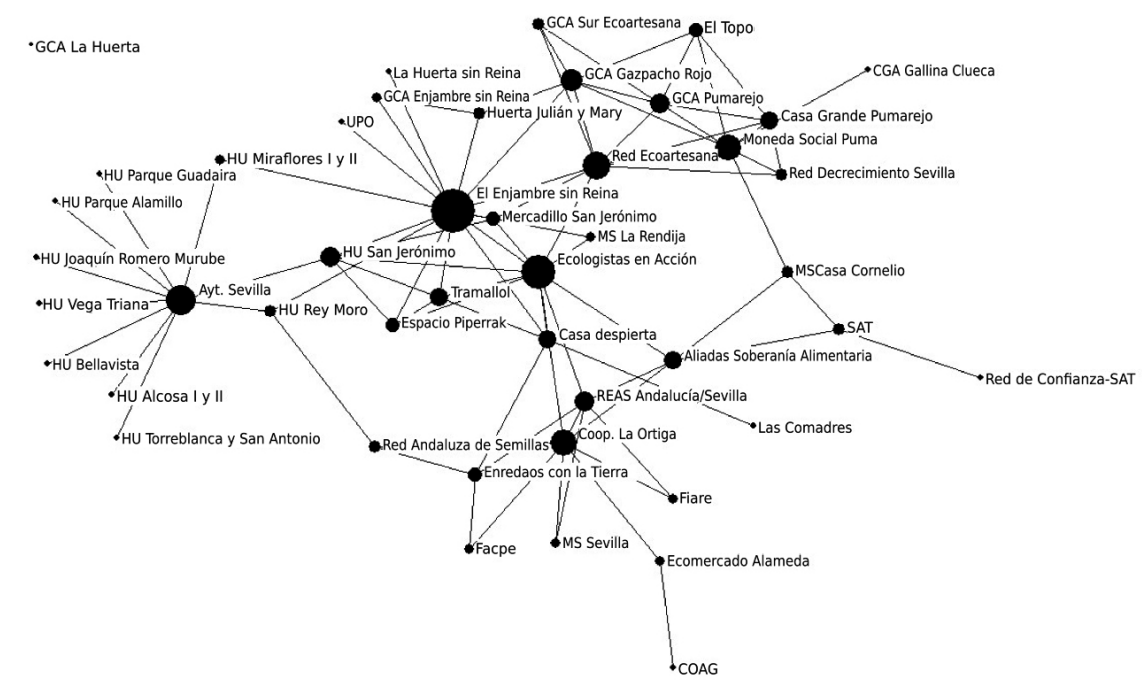

* La elaboración del sociograma se ha realizado con la ayuda del programa Ucinet. El tamaño de los nodos es proporcional a su centralidad, medida esta a partir del número de vínculos directos que establecen con los otros nodos.

Fuente: elaboración propia.

y socialización, han favorecido la difusión del ideario de movimientos alternativos promotores e impulsores de nuevas prácticas y, en algunos casos, han cedido sus locales para la recogida de cestas por grupos de consumo agroecológico.

\subsection{Pautas de localización de las prácticas alimentarias alternativas}

La diversidad de prácticas que se insertan en las RAA conlleva, además, diferentes comportamientos espaciales (mapa 1). Los huertos urbanos poseen una ubicación dispersa y mayoritariamente periférica, pese a ello, también se pueden encontrar en el interior del núcleo urbano. Es el caso del Huerto del Rey Moro, ubicado en el borde oriental del casco antiguo. La localización de bancos de semillas es también periférica, pues aprovechan las instalaciones de algunos de estos huertos, como el de San Jerónimo.

Respecto a los mercados de productores agrarios, estos se celebran en espacios públicos abiertos y los existentes tienen lugar en dos de los de mayor simbolismo y visibilidad para las prácticas económicas alternativas y las RAA: la Alameda de Hércules y el parque de San Jerónimo.

La ubicación de los locales de las asociaciones de productores y consumidores, así como de cooperativas y grupos de consumo agroecológico, presenta una marcada tendencia a la concentración en la zona norte del casco antiguo, lo que parece estar condicionado por varios factores. Uno de ellos es la proximidad a otras prácticas económicas alternativas, que tienden a agruparse en 
los barrios de San Julián, San Gil, Feria y San Vicente (González-Romero y Caravaca, 2020). En estos barrios todavía se encuentran numerosos edificios en desuso, algunos de los cuales son antiguos talleres artesanales y establecimientos fabriles. El estado y las características de los inmuebles de este sector urbano los hace especialmente proclives a su okupación, y algunos de ellos son un referente para los movimientos sociales más combativos y contestatarios, que convergen en estos barrios con asociaciones vecinales especialmente activas. No es extraño que algunas iniciativas alimentarias compartan locales con otras prácticas económicas alternativas (Casa Grande del Pumarejo, Tramallol, Ecolocal...) o con sindicatos (SAT).

Por su parte, el perfil ideológico resulta un factor influyente en la aparición de prácticas económicas alternativas, entre las que se encuentran las alimentarias. Los barrios del sector norte del casco antiguo han estado vinculados tradicionalmente a la izquierda política, tendencia que se ha reforzado tanto por la crisis como por la llegada de nuevos residentes. A partir de los comicios municipales de 2015, los barrios de San Gil, San Julián y Feria son los que concentran los porcentajes más altos de votos a los partidos y coaliciones más de izquierdas (Participa Sevilla, Ganemos Sevilla, Unidas Podemos...), que se convierten en los más votados en algunas de sus secciones (INE, 2015; Sánchez et al., 2018; Sánchez y Figueroa, 2019; Sánchez, Ferreiro et al., 2019; Sánchez, Figueroa et al., 2019).

Otro factor, aunque de menor importancia, es la proximidad a los consumidores. Según la información disponible de trabajos previos y por las entrevistas, en el área septentrional del casco antiguo y en barrios contiguos, como el de la Macarena, reside un número significativo de los consumidores, pero son también muchos los que proceden de otros sectores de la ciudad (GonzálezRomero y Torres Gutiérrez, 2019). La alta implicación personal de los participantes en este tipo de iniciativas motiva que otorguen una consideración menor a los desplazamientos hacia los lugares de abastecimiento. Aun así, existen proyectos con varios locales (cooperativa La Ortiga) y repartos de cestas a grupos de consumo por diferentes distritos.

\subsection{Redes alimentarias alternativas y espacio urbano: áreas de concentración}

El análisis de la distribución intraurbana de las iniciativas que conforman las RAA en la ciudad evidencia su concentración de forma significativa en el sector norte del casco antiguo. Esta zona es un espacio complejo que, en las últimas décadas, se ha visto inmerso en un proceso de transformación y rehabilitación urbanística, al que ha seguido otro de sustitución de parte de su tejido social. Caracterizado por su heterogeneidad social y espacial, en él coexisten espacios con situaciones divergentes: depauperados y envejecidos versus renovados y rejuvenecidos, tradicionales versus modernizados, entre los que se reparten grupos sociales con perfiles y estilos de vida muy diferenciados.

La transformación urbanística de esta zona comienza en los últimos años del siglo xx con el Plan Urban de la Unión Europea, cuyo objetivo era la 
Mapa 1. Mapa de las prácticas alimentarias alternativas en la ciudad de Sevilla, 2000-2020

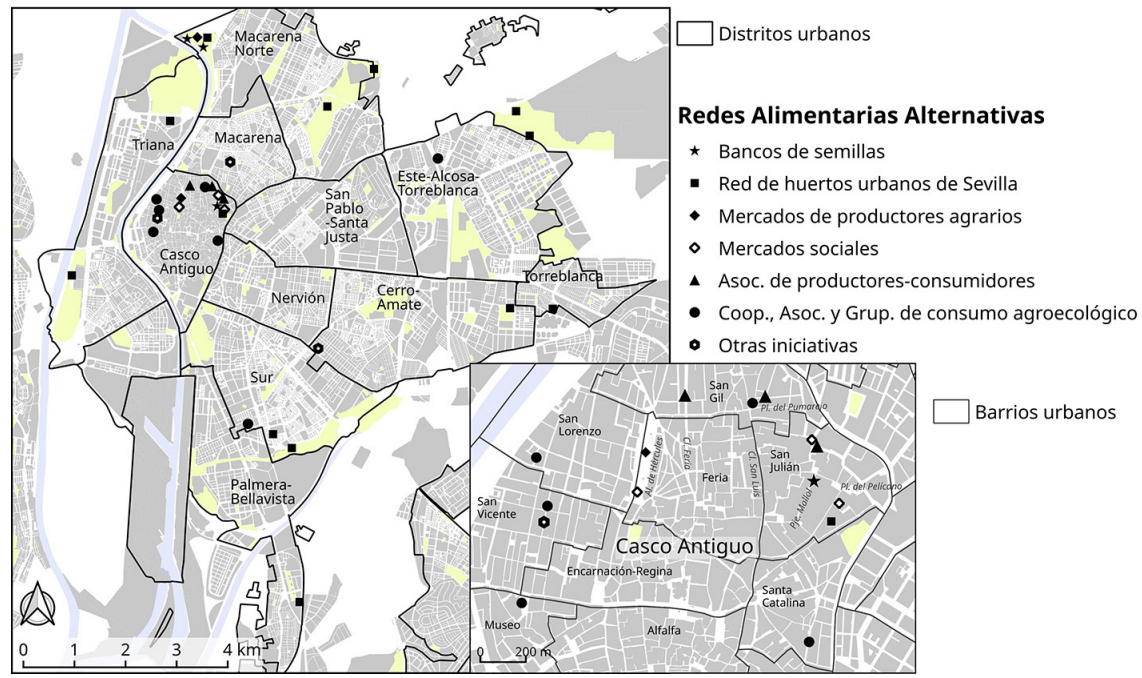

Fuente: elaboración propia a partir de entrevistas y webs de diferentes colectivos $(<\mathrm{https}$ ://sevillaecoartesana.wordpress.com>, <https://www.ecoagricultor.com>, <https://laortiga.com>, http://enredaosconlatierra. org >, <https://redandaluzadesemillas.org >, <https://www.facpe.org/productores $>$ ).

regeneración de ámbitos urbanos en crisis. La zona septentrional del casco antiguo hacía décadas que presentaba problemas de desempleo y marginación social, a los que se sumaba su deterioro urbanístico, por lo que fue objeto de intervención, muy especialmente, el entorno de la calle San Luis.

$\mathrm{Al}$ proceso de rehabilitación y regeneración urbanística, le siguió otro de gentrificación que supuso la expulsión de parte de las clases sociales modestas y marginales, mientras otra parte permaneció gracias a un importante activismo vecinal (Cantero et al., 1999; Díaz, 2014). Los nuevos residentes y sujetos gentrificadores se caracterizaron no tanto por sus niveles de renta, sino por buscar zonas alternativas con ambientes contraculturales. Recientemente, la creciente turistización de este ámbito ha activado nuevamente el movimiento vecinal a través de diferentes colectivos (Díaz y Jover, 2018; Jover et al., 2018).

Dentro del casco antiguo se identifican cuatro focos principales de concentración de iniciativas alimentarias alternativas en los barrios de San Gil, San Julián, Feria, San Vicente y San Lorenzo (mapa 1). En cada uno, se identifican proyectos y espacios públicos con una importante carga simbólica para los movimientos ciudadanos más combativos frente al capitalismo, así como para las corrientes contraculturales y los ambientes creativos de la ciudad.

En el barrio de San Gil se encuentra la plaza de El Pumarejo, donde se localiza una casa palacio del siglo XVIII que acoge un centro autogestionado okupado símbolo de la lucha vecinal contra la especulación. Al mismo se ha vinculado un grupo de consumo agroecológico y cerca se encuentra la sede del SAT, que impulsó una red de productores y consumidores agroecológicos. 
En el barrio de San Julián las RAA se agrupan en torno a la plaza del Pelícano. En la misma se localizó el mercado social Casa Cornelio del SAT y en una calle aledaña está el Huerto del Rey Moro, un espacio comunitario surgido de la okupación vecinal de un antiguo huerto junto a una residencia del siglo XV. En calles próximas se encuentran Tramallol, que da cabida a la iniciativa de cultivo urbano Piperrak, el proyecto de El Enjambre sin Reina y el mercado social La Rendija.

En el barrio de Feria existe un lugar central, la Alameda de Hércules (del siglo XVI) que, tras su transformación en las últimas décadas, ha pasado de foco de droga y prostitución a uno de los espacios que atraen a la vanguardia artística y cultural de la ciudad y donde se encuentran algunos de los locales más alternativos. En este bulevar se celebra un ecomercado impulsado por la Coordinadora de Organizaciones de Agricultores y Ganaderos (COAG) y también ha acogido diferentes ferias del Mercado Social de Sevilla, promovidas, igual que en otras ciudades, por la Red de Economía Alternativa y Solidaria.

En los barrios de San Vicente y San Lorenzo se han localizado varios proyectos, entre los que sobresale la cooperativa de consumo ecológico La Ortiga, una de las más veteranas de Andalucía y a la que se sumaron otros proyectos, algunos ya inactivos.

Fuera del casco antiguo hay que destacar otra zona de concentración en el parque de San Jerónimo, al noroeste. En este espacio, donde se ubica la sede de Ecologistas en Acción, se encuentran iniciativas alentadas o colaboradas por esta organización: un huerto urbano, dos bancos de semillas y un mercado de productores agrarios.

\subsection{Redes alimentarias alternativas y espacios rurales integrados}

Los productores que participan de las RAA en Sevilla, según los identificados en las entrevistas y en diferentes webs, son mayoritariamente agrarios (51\% agrícolas y 3,6\% ganaderos), no siendo desdeñable la presencia de otros productores, fundamentalmente de aceites, quesos y vinos (46,4\%). Tal y como se comprueba en el mapa 2, se aprecian dos áreas de concentración: la sierra de Aracena y la aglomeración urbana de Sevilla, mientras que el resto se localizan de forma más dispersa por el territorio.

La distribución geográfica de estos productores está determinada por el tipo de alimento que suministran y el tipo de práctica en la que participan. Así, quienes surten de productos frescos, como cabría esperar, están más próximos a la ciudad que los que abastecen de alimentos elaborados. En cuanto a las prácticas, se establecen diferencias en la localización de los productores que se relacionan con el grado de compromiso que se alcanza entre productor y consumidor. En las asociaciones de productores-consumidores y los grupos de consumo agroecológico, el alto grado de imbricación y compromiso entre productor y consumidor, así como el conocimiento y los vínculos que se establecen entre unos y otros, explica que los productores sean de la aglomeración urbana de Sevilla y de municipios cercanos, aunque la red puede llegar a exten- 
Mapa 2. Mapa de la red de los productores que abastecen a las redes alimentarias alternativas de la ciudad de Sevilla, 2007-2020

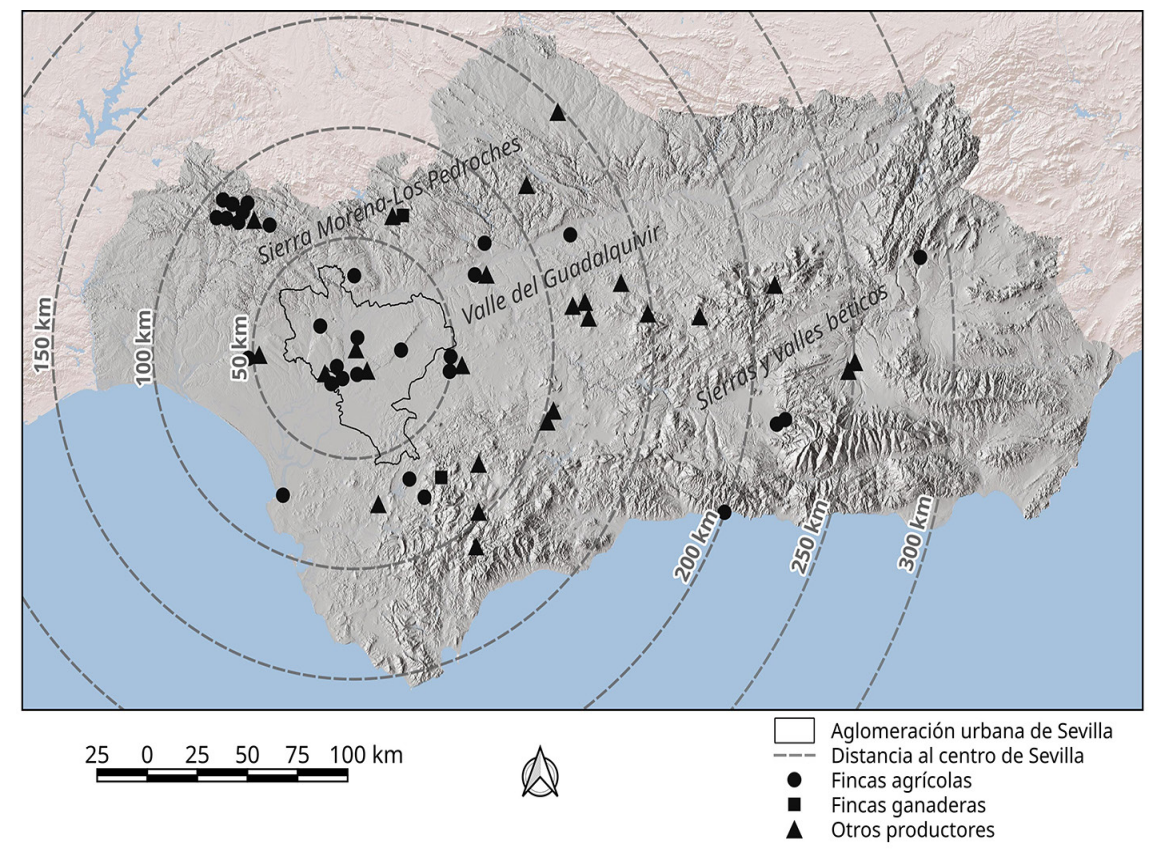

Fuente: elaboración propia a partir de entrevistas y webs de diferentes colectivos (<https://sevillaecoartesana.wordpress.com>, <https://www.ecoagricultor.com>, <https://laortiga.com>, <http://enredaosconlatierra. org $>,<$ https://redandaluzadesemillas.org $>,<$ https://www.facpe.org/productores $>$ ).

derse hasta los $100 \mathrm{~km}$. La proximidad física facilita la proximidad económica, social y cultural entre campesino y consumidor, inexorablemente unidas a las prácticas alimentarias alternativas. Considerando el criterio km 0 (distancia menor de $100 \mathrm{~km}$ ) y calculando la distancia por carretera (no como un área de amortiguación circular o buffer), se tiene que cumplen con este criterio el $82,1 \%$ de los productores agrícolas y el 63,6\% de los otros productores.

En el caso de los mercados de productores agrarios, mercados sociales y cooperativas de consumidores, la red se puede extender a mayor distancia y abarcar territorios más alejados. Los vínculos que se establecen entre productores y consumidores, salvo para los mercados de productores agrarios, no se realizan cara a cara, y los compromisos entre productor y consumidor son más laxos que los que se originan en las asociaciones de productoresconsumidores y los grupos de consumo agroecológico. Además, entre los alimentos que se adquieren a través de estas prácticas, tienen mayor importancia los elaborados y los frescos que, por motivos agroclimáticos, tienen poca o ninguna presencia en Andalucía. En estos casos, la proximidad física productor-consumidor pasa a un segundo nivel, y cobra mayor importancia 
la económica, social y cultural. Así se explica que en algunas entrevistas se haya hecho referencia a la provisión de alimentos procedentes de territorios más alejados. Ese parece ser el caso para el abastecimiento de frutas de otras zonas de España, como La Rioja, Murcia, Navarra, Cataluña y Canarias, y de las importaciones de pasta o café.

\section{Discusión y conclusiones}

La proliferación de RAA se relaciona con las críticas hacia el modelo agroalimentario imperante y la defensa de una agricultura y una ganadería de los campesinos que, a través de canales cortos de comercialización, los aproximen a los consumidores. Estas redes prosperan en los ámbitos urbanos, donde confluyen ciudadanos movilizados frente al orden establecido, colectivos afectados por la crisis y quienes se ven atraídos por una nueva cultura de la alimentación. En este artículo ha interesado destacar, especialmente, las implicaciones territoriales de las RAA a partir de las experiencias habidas en la ciudad de Sevilla.

Las preguntas iniciales de investigación sirven ahora para orientar la discusión y apuntar algunas conclusiones:

¿Qué presencia tienen las RAA en la ciudad de Sevilla?, ¿cuál ha sido su evolución? Las RAA proliferan en ámbitos urbanos y surgen asociadas a movimientos sociales que persiguen la construcción de un sistema de distribución y un orden alimentario alternativo que tienen por objeto la transformación social y ecológica (Whatmore y Thorne, 1997; Winter, 2003; Watts et al., 2005; Maye et al., 2007). La dimensión de la aglomeración urbana de Sevilla, la cuarta en España, ha podido influir en cuanto a potenciales productores y consumidores de estas redes de alimentación. Aunque su presencia en la ciudad de Sevilla es anterior, la crisis de 2008 favoreció su crecimiento, al igual que sucediera con otras prácticas económicas alternativas en ciudades españolas (Sánchez Hernández, coord., 2019). Aunque en menor medida que otras iniciativas alternativas, estas prácticas agroecológicas también se han visto afectadas por un proceso de institucionalización (Fernández y Miró, 2016; Méndez, 2018; Sánchez Hernández y Glückler, 2019), especialmente en lo relativo a los huertos urbanos.

\section{¿Quiénes son sus actores?, ¿cómo se conectan?}

La base social sobre la que se sustentan las RAA la conforman agentes «culturalmente transformadores", como los denomina Conill et al. (2012), vinculados a movimientos sociales en defensa del medio ambiente, de la soberanía alimentaria y de los bienes comunales, y frente a la globalización y el capitalismo. Pero también están presentes colectivos más vulnerables, movidos por la necesidad, y aquellos otros que lo hacen atraídos por hábitos alimentarios más saludables (Michelini et al., 2017). Unos y otros están presentes en las RAA de Sevilla, y destacan entre los promotores los que proceden de núcleos de militancia política y activismo ciudadano. 
Al igual que ha sucedido en otras ciudades y en otras prácticas económicas alternativas, en Sevilla, los actores establecen una red de relaciones sustentadas sobre el conocimiento mutuo, la confianza colectiva y las identidades compartidas, que resultan claves para su generación y reproducción. Su organización y funcionamiento se sostienen sobre vínculos transversales, en los que predominan los internos y locales.

¿Qué relación existe entre dichas prácticas y el espacio urbano?, ¿existen ámbitos especificos con cierto grado de concentración?, ¿qué factores las propician?

Las RAA se concentran en la zona norte del casco antiguo, un sector donde se yuxtaponen barrios de origen modesto y otros donde la burguesía ha tenido mayor presencia. Actuaciones de renovación urbanística de las últimas décadas los han hecho especialmente atractivos para las vanguardias culturales y creativas, así como para la contracultura, pero también para los movimientos sociales más contestatarios y combativos frente al orden establecido. Unos y otros plasman en este espacio anhelos y aspiraciones. Los primeros descubren un espacio alternativo, renovado, que acoge profesiones y algunas de las propuestas más creativas de la ciudad, con la proyección de su imagen más contemporánea (García García et al., 2016). Los segundos encuentran un lugar para la protesta y la acción, pues en el mismo confluyen operaciones de regeneración urbana e intereses especulativos que afectan a grupos vulnerables, a veces envejecidos y pauperizados, con una trayectoria vecinal reivindicativa.

Se evidencia con ello que las pautas de distribución espacial de las RAA, como otras iniciativas económicas alternativas, coinciden con espacios socialmente innovadores (Michelini et al., 2017), tal como recoge la literatura. Se detectan, pues, concentraciones tanto en barrios de grupos más vulnerables, en respuesta a la exclusión social (Moulaert et al., 2010), como en entornos urbanos progresistas y de clase media motivados por razones ideológicas o éticas (Blanco et al., 2014).

¿Qué territorios se incorporan en estas RAA?, ¿hasta dónde se extienden?

La intensidad de la incorporación de los territorios a las RAA está relacionada con la cercanía a la ciudad de Sevilla. La cuestión del lugar es de gran importancia en el abastecimiento de productos, especialmente cuando son frescos. Según la información manejada, alrededor del $80 \%$ de los productores de alimentos frescos que distribuyen en estas redes proceden de lugares a menos de $100 \mathrm{~km}$ por carretera, entre los que destacan los de la sierra de Aracena y, en menor medida, los de la sierra de Cádiz y sierra Norte de Sevilla; las RAA se presentan, así, como una oportunidad para el aprovechamiento agrícola de terrenos de montaña con cierto grado de marginalidad.

En definitiva, en la ciudad de Sevilla se ha desarrollado un denso tejido de iniciativas vinculadas a alternativas alimentarias que están arraigadas en determinados barrios, donde se reproducen, y cuyas implicaciones territoriales sobrepasan el ámbito periurbano, hasta alcanzar el regional e incluso el nacional e 
internacional (este último de forma más anecdótica). La mayor densidad de estas prácticas en determinados sectores se relaciona tanto con su trayectoria urbana como con el perfil socioeconómico, cultural e ideológico de sus protagonistas. Aunque este hecho cuestiona, en parte, la replicabilidad de dichas prácticas, no puede dejar de valorarse su capacidad para generar proyectos colectivos y aglutinar intereses en favor de un sistema alimentario más justo y sostenible.

\section{Agradecimientos}

Los autores desean expresar su agradecimiento a las personas que han colaborado en esta investigación participando en las entrevistas, así como a los revisores, que han aportado sugerencias muy valiosas.

\section{Referencias bibliográficas}

Alberdi Collantes, Juan Cruz (2018). «Agricultura ecológica y de proximidad como herramienta para el desarrollo rural: el ejemplo de San Sebastián». Ager. Revista de Estudios sobre Despoblación y Desarrollo Rural, 24, 191-224. $<$ https://doi.org/10.4422/ager.2017.09>

A-LIADAS POR LA SOBERANÍA ALIMENTARIA. < https://aliadasporlasoberania.blogspot. com/> [Consulta: 25 de mayo de 2020].

Altieri, Miguel (1987). Agroecology: the Scientific Basis of Alternative Agriculture. Boulder Colorado: Westview Press.

Aparicio, Javier; Sánchez, José Luis; Alonso, José Luis y Rodero, Valerio (2008). «La Ribera del Duero, geografía de un medio innovador en torno a la vitivinicultura». Scripta Nova. Revista Electrónica de Geografía y Ciencias Sociales, 12, 256-280.

Armesto López, Xosé A. (2007). «El concepto de agricultura ecológica y su idoneidad para fomentar el desarrollo rural sostenible». Boletin de la Asociación de Geógrafos Españoles, 43, 155-172.

Ayuntamiento de Sevilla (2018). Red de huertos urbanos de la ciudad de Sevilla. Bases y Estrategias para la creación e integración de una Red de Huertos Urbanos en la ciudad de Sevilla. Recuperado de <https://www.urbanismosevilla.org/areas/ planeamiento-desa-urb/huertos-urbanos-de-sevilla>.

Barnes, Trevor y Christophers, Brett (2018). Economic Geography. A Critical Introduction. Hoboken: Wiley.

Barrera Algarín, Evaristo; Sarasola Sánchez-Serrano, José luis y Malagón Siria, José Carlos (2017). «Resurgimiento comunitario ante la nueva realidad socioeconómica». REVESCO. Revista de Estudios Cooperativos, 124, 9-31.

Benito del Pozo, Paz y López-GonzÁlez, Alejandro (2019). «Urban Resilience and the Alternative Economy: a Methodological Approach Applied to Northern Spain». Geographical Review, 110 (3), 322-340. <https://doi.org/10.1080/00167428.2019.1684195>

Blanco, Ismael; Brugué, Joaquim y Cruz-Gallach, Helena (2014). «Resiliencia comunitaria frente a la crisis: innovación social y capacidad cívica en los barrios desfavorecidos». En: AA.VV. V Congreso Internacional en Gobierno, Administración y Políticas Públicas. Recuperado de <http://www.gigapp.org/index.php/comunidad-gigapp/publication/show/1778>. 
Blanco, Ismael; Cruz Gallach, Helena; Martínez Moreno, Rubén y Parés, Marc (2016). «El papel de la innovación social frente a la crisis». Ciudad y Territorio Estudios Territoriales, XLVIII (188), 249-260.

Borgatti, Stephen; Everett, Martin G. y Johnson, Jeffrey C. (2013). Analyzing social networks. Londres: SAGE.

Burch, David y Lawrence, Geoffrey (2009). "Towards a third food regime: behind the transformation». Agriculture and Human Values, 26 (4), 267-279. $<$ https://doi.org/10.1007/s10460-009-9219-4>

Calle, Angel; Soler, Marta y VAra, Isabel (2009). «La desafección al sistema agroalimentario: ciudadanía y redes sociales». En: Actas del I Congreso Español de Sociología de la Alimentación. Gijón: Universidad de Oviedo.

Callejo, Javier (2009). "La reorganización del sistema de confianza tras la crisis: el proceso en el campo de la alimentación». Revista Española de Sociología. Madrid: Federación Española de Sociología, 12, 39-65.

Cantero, Pedro A.; Escalera, Javier y García, Reyes (1999). La ciudad silenciada: vida social y Plan Urban en los barrios del Casco Antiguo de Sevilla. Sevilla: Ayuntamiento de Sevilla.

Caravaca, Inmaculada y González-Romero, Gema (2019). «Una mirada alternativa al desarrollo local. Las monedas sociales en la aglomeración urbana de Sevilla». Scripta Nova. Revista Electrónica de Geografía y Ciencias Sociales, xxIII, 621. <https://doi.org/10.1344/sn2019.23.22487>

Climent, Eugenio y Lardiés-Bosque, Raúl (2019). «Prácticas económicas alternativas y espacio urbano: el caso de Zaragoza». En: VV. AA. Crisis y espacios de oportunidad. Retos para la Geografía. Asociación de Geógrafos Españoles y Universidad de Valencia, 1.324-1.338.

Conill, Joana; Cárdenas, Amalia; Castells, Manuel; Hlebik, Svetlana y Servon, Lisa (2012). Otra vida es posible. Prácticas económicas alternativas durante la crisis. Barcelona: Ediciones UOC.

Corsi, Alessandro; Barbera, Filippo; Dansero, Egidio; Orlando, Giovanni y Peano, Cristina (eds.) (2018). Alternative Food Networks. Cham: Palgrave Macmillan. <https://doi.org/10.1007/978-3-319-90409-2>

Di IAcovo, Francesco (2010). "L'agricoltura sociale: pratiche e paradigmi nello scenario comunitario». XLVII Convegno di Studi de la Società Italiana di Economia Agraria "L'agricoltura oltre le crisi"”. Campobasso, Università degli Studi del Molise, 22-25 septiembre.

DíAZ, Ibán (2014). «La gentrificación, un regreso a la ciudad de la intervención urbanística». Boletín de la Asociación de Geógrafos Españoles, 64, 321-340. $<$ https://doi.org/10.21138/bage.1700>

DíAz, Ibán y Jover, Jaime (2018). "Enclaves urbanos de éxito. Transformación urbanística, gentrificación y turismo en la Alameda de Hércules de Sevilla». En: Gasca Zamora, J. (coord.). Capital inmobiliario y transformaciones del espacio urbano contemporáneo. México DF: Universidad Nacional Autónoma de México, 337-358.

Dimuro, Glenda (2016). La producción y gestión social de la agroecología urbana en Sevilla. Tesis doctoral.

Dimuro, Glenda; Soler Montiel, Marta y Manuel Jerez, Esteban de (2013). «La agricultura urbana en Sevilla: entre el derecho a la ciudad y la agroecología». Habitat y Sociedad, 6, 41-60. 
Diprose, Gradon (2017). «Radical equality, care, and labour in a community economy». Gender, Place \& Culture, 24, 834-850. <https://doi.org/10.1080/0966369X.2017.1339671>

Domene, Elena; Coll, Francesc y García-Sierra, Marta (2017). «Huertos agrarios, ¿en peligro de extinción? Su encaje en una propuesta integrada de gestión de la agricultura urbana y periurbana en el Área Metropolitana de Barcelona». En: VV. AA. Naturaleza, territorio y ciudad en un mundo global. XXV Congreso de la AGE. Madrid, 25-27 noviembre, 1.371-1.380.

Domínguez, Silvia y Hollstein, Betina (eds.) (2014). Mixed Methods Social Networks Research: Design and Applications. Nueva York: Cambridge University Press.

ECOAGRICUltor. <https://www.ecoagricultor.com/> [Consulta: 19 de mayo de 2020].

El Enjambre sin Reina. <https://elenjambresinreina.eu/> [Consulta: 25 de mayo de 2020].

EnRedaOS CON LA Tierra. <http://enredaosconlatierra.org/> [Consulta: 21 de mayo de 2020].

Esteban Rodríguez, Samuel y Climent López, Eugenio (2017). «Los mundos de producción de las denominaciones de origen protegidas del vino en España: disparidad de convenciones tecnológicas y comerciales». Economía Agraria y Recursos Naturales, 17 (1), 101-125.

<https://doi.org/10.7201/earn.2017.01.05>

FACPE. <https://www.facpe.org/productores/> [Consulta: 21 de mayo de 2020].

Fernández, Anna y Miró, Iván (2016). Economía social solidaria en Barcelona. Barcelona: Comissionat d'Economia Cooperativa, Social i Solidària - Ajuntament de Barcelona. Recuperado de <http://www.laciutatinvisible.coop/wp-content/ uploads/2016/02/essb_def3.pdf>.

Fickey, Amanda (2011). "The Focus Has to be on Helping People Make a Living': Exploring diverse economies and alternative economic spaces». Geography Compass, 5, 237-248. <https://doi.org/10.1111/j.1749-8198.2011.00418.x>

Fickey, Amanda y Hanrahan, Kelsey B. (2014). «Moving beyond "Neverland": reflecting upon the diverse economies research program and the study of alternative economic spaces». ACME: An International E-Journal for Critical Geographies, 13, 394-403.

Freitas, Silvia y Canto, Consuelo del (2014). «Desarrollo territorial, gobernanza y denominaciones de origen: el estudio de las DO's vitivinícolas de Méntrida, Mondéjar y Uclés». Anales de Geografía de la Universidad Complutense, 65-95.

García García, Antonio; Fernández Salinas, Víctor; Caravaca Barroso, Inmaculada y González-Romero, Gema (2016). «Actividades creativas, transformaciones urbanas y paisajes emergentes. El caso del casco norte de Sevilla». Documents d'Anàlisi Geogràfica, 62 (1), 27-54. <http://dx.doi.org/10.5565/rev/dag.245>

García-Llorente, Marina; Rossignoli, Cristiano M.; Di Iacovo, Francesco y Moruzzo, Roberta (2016). "Social farming in the promotion of social-ecological sustainability in rural and periurban areas». Sustainability, 8 (12), 1.238. <https://doi.org/10.3390/su8121238>

Gibson-Graham, J. K. (1997). "The end of capitalism (as we knew it). A feminist critique of political economy». Capital \& Class, 21 (2), 186-188.

- (2006). A post-capitalist politics. Minneapolis: University of Minnesota Press. 
- (2007). "Cultivating subjects for a community economy». En: Tickell, Adam; Sheppard, Eric; Peck, Jamie y Barnes, Trevor (eds.). Politics and Practice in Economic Geography. Londres: SAGE, 106-118.

- (2008). "Diverse economies: performative practices of "other worlds"». Progress in Human Geography, 32, 613-632. <https://doi.org/10.1177\%2F0309132508090821>

Gliessman, Stephen R. (2007). Agroecology: The ecology of Sustainable Food System. Boca Ratón: CRC Press.

Goldberg, Robert A. (1991). Grassroots Resistance: Social Movements in Twentieth Century America. Belmont, CA: Wadsworth Publishing Company.

GonzÁlez-Romero, Gema y Torres Gutiérrez, Francisco José (2019). «Espacios y prácticas económicas alternativas». En: Sánchez Hernández, José Luis (coord.). Espacios y prácticas económicas alternativas en las ciudades españolas. Cizur Menor (Navarra): Thomson Reuters Aranzadi, 257-276.

González-Romero, Gema y Caravaca Barroso, Inmaculada (2020). Prácticas económicas alternativas en la ciudad de Sevilla. Boletín de la Asociación de Geógrafos Españoles, 87. <https://doi.org/10.21138/bage.2959>

Goodman, David y Goodman, Michael (2009). «Food Networks, Alternative». En: Kitchin, Rob y Thrift, Nigel (eds.). International Encyclopaedia of Human Geography. Amsterdam: Elsevier, 208-220.

Goodman, David; Dupuis, E. Melanie y Goodman, Michael K. (2012). Alternative food networks: Knowledge, practice, and politics. Londres: Routledge.

Gritzas, Giorgos y Kavoulakos, Karolos Iosif (2016). «Diverse economies and alternative spaces: An overview of approaches and practices». European Journal and Regional Studies, 23 (4), 917-934. <https://doi.org/10.1177/0969776415573778>

Guirado, Carles; Valldeperas, Natalia; Tulla, Antoni F. y Vera, Ana (2018). «La agricultura social en Cataluña: diagnosis de un fenómeno emergente». Boletín de la Asociación de Geógrafos Españoles, 77, 148-185. <https://doi.org/10.21138/bage.2537>

Guzmán, Gloria; González de Molina, Manuel y Sevilla Guzmán, Eduardo (2000). Introducción a la agroecología como desarrollo rural sostenible. Madrid: Ed. MundiPrensa.

Harris, Edmund M. (2010). «Eat local? Constructions of place in alternative food politics». Geography Compass, 4 (4), 355-369. <https://doi.org/10.1111/j.1749-8198.2009.00298.x>

Healey, Stephen (2009). «Economies, Alternative». En: Kitchin, Rob y Thrif, Nigel (eds.). International Encyclopedia of Human Geography, I, 338-344.

Huerto Del Rey Moro. <http://www.huertodelreymoro.org/historia-del-huerto-delrey-moro/> [Consulta: 18 de mayo de 2020].

INE (2015). «Base de datos de resultados electorales del Instituto Nacional de Estadística». Recuperado de <https://www.ine.es>.

JAROSZ, Lucy (2008). "The city in the country: growing alternative food networks in metropolitan areas». Journal of Rural Studies, 24, 231-244. <https://doi.org/10.1016/j.jrurstud.2007.10.002>

Jones, Andrew y Murphy, James Thomas (2011). "Theorizing practice in economic geography: Foundations, challenges and possibilities». Progress in Human Geography, 35 (3), 366-392. <https://doi.org/10.1177/0309132510375585> 
Jover, Jaime; Berraquero-Díaz, Luis; Barrero-Rescalvo, María y Jiménez-TalaVER, Ana (2018). «Turistización y movimientos urbanos de resistencia: experiencias desde Sevilla». En: Milano, Claudio y Mansilla, José (coords.). Ciudad de vacaciones. Conflictos urbanos en espacios turísticos. Barcelona: Pol-hen Edicions, 403-437.

LA Ortiga. <https://laortiga.com/> [Consulta: 20 de mayo de 2020].

Larrubia Vargas, Remedios; Natera Rivas, Juan José y Carruana Herrera, David (2020). «Los huertos urbanos como estrategia de transición urbana hacia la sostenibilidad en la ciudad de Málaga». Boletín de la Asociación de Geógrafos Españoles, 86. <https://doi.org/10.21138/bage.2972>

Leyshon, Andrew; Lee, Roger y Williams, Colin C. (eds.) (2003). Alternative economic spaces. Londres: SAGE.

López García, M. Rosa (1999). «La agricultura ecológica en el quehacer científico. Tema incipiente en la geografía». Anales de Geografía de la Universidad Complutense, 19, 351-364.

López García, Daniel (2015). Producir alimentos, reproducir comunidad. Redes alimentarias alternativas como formas económicas para la transformación social y ecológica. Madrid: Libros en Acción.

López Ontiveros, Antonio y Moya, José (1994). «Agricultura ecológica, medio ambiente y desarrollo rural». En: AA. VV. Actas del VII Coloquio de Geografía Rural. Córdoba: Servicio de Publicaciones de la Universidad de Córdoba, 208-215.

Loscertales, Blanca; Escalona, Ana Isabel y Climent, Eugenio (2011). "Cambios recientes en el sector vitivinícola: el caso de las denominaciones de origen zaragozanas». Geographicalia, 59-60, 227-240.

Mardden Terry, Banks Jo y Bristow, Gillian (2000). «Food supply chain approaches: exploring their role in rural development». Sociologia Ruralis, 4, 424-438. <https://doi.org/10.1111/1467-9523.00158>

Mata Olmo, Rafael (2018). «Agricultura periurbana y estrategias agroalimentarias en las ciudades y áreas metropolitanas españolas. Viejos problemas, nuevos proyectos». En: Cultura territorial e innovación social: ¿Hacia un nuevo modelo metropolitano en Europa del Sur? Valencia: PUV, 369-390.

Maye, Damian; Holloway, Lewis y Kneafsey, Moya (eds.) (2007). Alternative food geographies. Representation and practice. Amsterdam: Elsevier.

McMichael, Philip (2009). "A food regime analysis of the world food crisis». Agriculture and Human Values, 26 (4), 281-295. <https://doi.org/10.1007/s10460-009-9218-5>

MÉndeZ GutiérReZ del VALLE, Ricardo (2015). «Redes de colaboración y economía alternativa para la resiliencia urbana: una agenda de investigación». Biblio3W, xx, 1.139.

- (2018). «Redes económicas alternativas ¿para una sociedad postcapitalista? Algunas experiencias en Madrid». En: AAVV. Las ciencias sociales y la edificación de una sociedad post-capitalista. Actas del XV Coloquio Internacional de Geocritica, 1-22.

- (2020). "Desafíos de futuro para la investigación en Geografía Económica». En: Alonso Logroño, Pilar; Sá Marques, Teresa y Santos, Helder (coord.). La Geografía de las Redes Económicas y la Geografía Económica en Red. Oporto: Faculdade de Letras da Universidade do Porto, Asociación de Geógrafos Españoles, 17-20. <https://doi.org/10.21747/9789898969460/geoa2>

Méndez Gutiérrez del Valle, Ricardo y Monteserín Abella, Obdulia (2017). «Redes alimentarias alternativas en grandes ciudades: los mercados de productos agrarios en Madrid». Cuadernos Geográficos, 56, 193-216. 
Michelini, Juan José; Méndez, Ricardo y Abad, Luis (2017). «Movilización social y alternativas alimentarias en áreas urbanas: los grupos de consumo agroecológico en Madrid». Ciudady Territorio Estudios Territoriales (CyTET), 49, 194, 679-698.

Molina, José Luis (2001). El análisis de redes sociales. Una introducción. Barcelona: Edicions Bellaterra.

Moulaert, Frank; Martinelli, Flavia; Swyngedouw, Erik y González, Sara (2010). Can Neighbourhoods Save the City? Londres: Routledge.

North, Peter (2005). «Scaling alternative economic practices? Some lessons from alternative currencies». Transactions of the Institute of British Geographers, 30 (2), 221-233. <https://doi.org/10.1111/j.1475-5661.2005.00162.x>

Pascual, Henar; Gil Álvarez, Esther y Guerra, Juan Carlos (2018). «Práctica social, economía alternativa y espacios de proximidad en la ciudad de Valladolid». Recerca. Revista de Pensament i Anàlisi, 23, 193-218. <http://dx.doi.org/10.6035/Recerca.2018.23.9>

Patel, Raj (2009). «Food sovereignty». The Journal of Peasant Studies, 36 (3), 663-706. <https://doi.org/10.1080/03066150903143079>

Psarikidou, Katerina y SzersZynsKi, Bronislaw (2012). «Growing the social: alternative agrofood networks and social sustainability in the urban ethical foodscape». Sustainability. Science, Practice \& Policy, 8 (1), 30-39.

Puente, Raúl (2012). Los huertos urbanos de Sevilla: de la tradición a la novedad. Sevilla: Diputación de Sevilla.

Red Andaluza de Semillas. Recuperado de <https://www.redandaluzadesemillas.org/ sites/default/files/recursos/2020/200212\%20DirectorioProductores_verFINAL. pdf> [Consulta: 19 de mayo de 2020].

ReD ECOARTESANA. <https://sevillaecoartesana.wordpress.com/> [Consulta: 23 de abril de 2020].

Renting, Henk; Marsden, Terry y Banks, Jo (2003). «Understanding Alternative Food Networks: Exploring the Role of short food supply chains in Rural Development». Environment and Planning A, 35 (3), 393-411. $<$ https://doi.org/10.1068/a3510>

SAGE, Colin (2003). "Social embeddedness and relations of regard: alternative "good food" networks in South-West Ireland». Journal of Rural Studies, 19, 47-60. <https://doi.org/10.1016/S0743-0167(02)00044-X>

Sánchez, Raúl; Figueroa, Héctor y Ordaz, Ana (3 de diciembre de 2018). «Mapa. ¿Qué votaron tus vecinos en las elecciones andaluzas? Los resultados electorales, calle a calle». Eldiario.es. Recuperado de <https://www.eldiario.es/andalucia/ MAPA-partido-elecciones-andaluzas-manzana_0_842366730.html>.

Sánchez, Raúl y FigueroA, Héctor (2 de mayo de 2019). "¿Qué votaron tus vecinos en las elecciones generales? Los resultados del 28A por partido y por bloque izquierda-derecha, calle a calle». Eldiario.es. <https://www.eldiario.es/politica/ votaron-elecciones-generales-resultados-calle_0_894860668.html>.

Sánchez, Raúl; Ferreiro, David y Calejero, Alba (29 de mayo de 2019). "¿Qué votaron tus vecinos el 26M? Los resultados de las elecciones generales, calle a calle». Eldiario.es. Recuperado de <https://www.eldiario.es/politica/votaron-eleccionesmunicipales-resultados-calle_0_904309592.html>.

Sánchez, Raúl; Figueroa, Héctor; Pardo, Andrea; Barrio, Fernando y Álvarez, Pablo (11 de noviembre de 2019). «Mapa. ¿Qué votaron tus vecinos el 10N? Los resultados de las elecciones generales, calle a calle». Eldiario.es (Andalucía). 
Recuperado de <https://www.eldiario.es/politica/votaron-resultados-eleccionesgenerales-calle_0_962404599.html>.

SÁnchez Hernández, José Luis (2009). «Redes alimentarias alternativas: concepto, tipología y adecuación a la realidad española». Boletín de la Asociación de Geógrafos Españoles, 49, 185-207.

- (2017). Las prácticas económicas alternativas en perspectiva geográfica. Salamanca: Universidad de Salamanca.

- (coord.) (2019). Espacios y prácticas económicas alternativas en las ciudades españolas. Cizur Menor (Navarra): Thomson Reuters Aranzadi.

Sánchez Hernández, José Luis; Nicolás Penela, Adrián; Alonso Santos, José Luis y Moro GutiÉrRez, Lourdes (2017). «Regeneración urbana, innovación social y prácticas económicas alternativas en ciudades medias: el barrio del Oeste (Salamanca)». Ería. Revista Cuatrimestral de Geografía, 37, 67-82. <https://doi.org/10.17811/er.1.2017.67-82>

SÁNCHEZ HernáNDEZ, José Luis y GLÜCKLER, Johannes (2019). «Alternative economic practices in Spanish cities: from grassroots movements to urban policies? An institutional perspective». European Planning Studies, 27, 2.450-2.468. <https://doi.org/10.1080/09654313.2019.1644295>

Sevilla Guzmán, Eduardo y Soler Montiel, Marta (2010). «Agroecología y soberanía alimentaria: alternativas a la globalización agroalimentaria». En: SOlER Montiel, Marta y Guerrero Quintero, Carmen (coord.). Patrimonio cultural en la nueva ruralidad andaluza. Sevilla: Instituto Andaluz de Patrimonio Histórico, Consejería de Cultura, PH Cuadernos (26), 191-217.

Sevilla Guzmán, Eduardo; Soler Montiel, Marta; Gallar, David; Vara, Isabel y Calle Collado, Ángel (2012). Canales cortos de comercialización alimentaria en Andalucía. Centro de Estudios Andaluces, Consejería de la Presidencia e Igualdad, Junta de Andalucía. Recuperado de <https://www.juntadeandalucia.es/export/ drupaljda/CCC_alimentaria_en_Andalucia_2012.pdf>.

Sonnino, Roberta y Marsden, Terry (2006). «Beyond the divide: rethinking relationships between alternative and conventional food networks in Europe». Journal of Economic Geography, 6 (2), 181-199. $<$ https://doi.org/10.1093/jeg/lbi006>

Timmermann, Cristian; Félix, Georges F. y Tittonell, Pablo (2018). «Food sovereignty and consumer sovereignty: Two antagonistic goals?». Agroecology and Sustainable Food Systems, 42 (3), 274-298. <https://doi.org/10.1080/21683565.2017.1359807>

Tulla, Antoni F.; Guirado, Carles; Badía, Anna; Vera, Ana; Valldeperas, Natàlia y Evard, Camille (2015). «L'Agricultura Social a Catalunya. Una doble alternativa: desenvolupament local i ocupació de col-lectius en risc d'exclusió social». Quaderns Agraris, 38, 23-49.

Venn, Laura; Kneafsey, Moya; Holloway, Lewis; Cox, Rosie; Dowler, Elizabeth y Tuomainen, Helena (2006). "Researching European "alternative" food networks: some methodological considerations». Area, 38, 248-258. <https://doi.org/10.1111/j.1475-4762.2006.00694.x>

Vivas, Esther (2010). "Consumo agroecológico. Una opción política». Viento Sur, $108,54-63$.

Wasserman, Stanley y Faust, Katherine (1994). Social Network Analysis. Methods and Applications. Cambridge: Cambridge University Press. 
Watts, David C. H.; Ilbery, Brian y Maye, Damian (2005). «Making reconnections in agro-food geography: alternative systems of food provision». Progress in Human Geography, 29, 22-40. <https://doi.org/10.1191/0309132505ph526oa>

Whatmore, Sarah y Thorne, Lorraine (1997). "Nourishing networks: alternative geographies of food». En: Goodman, David y WatTs, Michael, J. (eds.). Globalising food. Agrarian questions and global restructuring. Londres: Routledge, 287-304.

White, Richard y Williams, Colin (2016). "Beyond capitalocentricism: are non capitalist work practices "alternatives"?». Area, 48, 325-331. $<$ https://doi.org/10.1111/area.12264>

WindfuHr, Michael y Jonsén, Jennie (2005). Food Sovereignty Towards democracy in localized food systems. Rugby, Warwickshire: TDG Publishing.

Winter, Michael (2003). «Geographies of food: Agro-food geographies - Making reconnections». Progress in Human Geography, 27, 505-513. <https://doi.org/10.1191/0309132503ph446pr>

Yacamán Ochoa, Carolina; Matarán Ruiz, Alberto; Mata Olmo, Rafael; Macías Figueroa, Álvaro y Torres Rodríguez, Adolfo (2020). «Peri-Urban Organic Agriculture and Short Food Supply Chains as Drivers for Strengthening City/ Region Food Systems - Two Case Studies in Andalucía, Spain». Land, 9 (6), 177. <https://doi.org/10.3390/land9060177>

Zademach, Hans Martin y Hildebrand, Sebastian (eds.) (2013). Alternative economies and spaces: new perspectives for a sustainable economy. Bielefeld: Transcript Verlag. Recuperado de <https://library.oapen.org/bitstream/id/ba4d2552-38754142-9ad7-8664dab6997f/627770.pdf>.

Zárate Martín, Manuel Antonio (2015). «Agricultura urbana, condición para el desarrollo sostenible y la mejora del paisaje». Anales de Geografía de la Universidad Complutense, 2 (35), 167-194.

<http://dx.doi.org/10.5209/rev_AGUC.2015.v35.n2.50119> 
